\section{Brazilian opinions} about science and technology: the 'paradox' of the relation between information and attitudes

\author{
Yurij Castelfranchi \\ Professor, Departmento de Sociologia/ \\ Universidade Federal de Minas Gerais (UFMG). \\ Av. Antônio Carlos, 6627 \\ 31270-901 - Belo Horizonte - MG - Brazil \\ ycastelfranchi@gmail.com \\ Elaine Meire Vilela \\ Professor, Departmento de Sociologia/UFMG. \\ Av. Antônio Carlos, 6627 \\ 31270-901 - Belo Horizonte - MG - Brazil \\ emvilela@gmail.com
}

Luciana Barreto de Lima

Statistician, Instituto de Avaliação e Desenvolvimento Educacional. Rua Madalena Sofia, 25

30380-650 - Belo Horizonte - MG - Brazil

lublbh@gmail.com

\section{Ildeu de Castro Moreira}

Professor, Instituto de Física/ Universidade Federal do Rio de Janeiro.

Avenida Athos da Silveira Ramos, 149,

Centro de Tecnologia, Bloco A, sala A-319

21941-972 - Rio de Janeiro - RJ - Brazil

ildeucastro@gmail.com

Luisa Massarani

Researcher, Center for Studies in Science

Communication at Museu da Vida/

Casa de Oswaldo Cruz/Fundação Oswaldo Cruz. Avenida Brasil, 4365

21045-900 - Rio de Janeiro - RJ - Brazil lumassa@fiocruz.br

Received for publication in January 2012. Approved for publication in November 2012.

Translated by Diane Grosklaus Whitty.
CASTELFRANCHI, Yurij et al. Brazilian opinions about science and technology: the 'paradox' of the relation between information and attitudes. História, Ciências, Saúde - Manguinhos, Rio de Janeiro, v.20, supl., nov. 2013. Available at: http://www.scielo.br/hcsm.

\section{Abstract}

In many debates on the relation between science and society, especially concerning the acceptance of technology or the perception of its risks, there is an underlying hypothesis: that ignorance generates fear, which in turn generates mistrust or hostility toward science and technology (S\&T). The article shows that this hypothesis is questionable. Based on a recent nationwide survey in Brazil, we show that optimistic attitudes about S\&T do not depend on people's educational level, their level of information, or their accessing of related subject matter. On average, respondents who say they have scarce information on the topic display positive attitudes. Those with a higher educational level and who access information display diverse attitudes, which are optimistic in some regards but more critical in others.

Keywords: public understanding of science; social studies of science and technology; science communication; Brazil. 
$\mathrm{n}$ recent decades, the social perception of science and technology (S\&T) has become a
prominent topic in both academia and the political world. Today, knowing people's attitudes and opinions about S\&T and the economic, political, or ethical implications of this subject matter is considered important when it comes to devising and assessing public policies. This information is also key in efforts to foster social inclusion, understand the processes involved in the acceptance or rejection of innovation, enhance models for popularizing science and improving science teaching, and comprehend the factors that might prompt a young person to opt for a career in science.

The present article analyzes some facets of the debate on the relation between information and attitudes toward S\&T. Relying on the findings of a recent nationwide survey (Brasil, 2010) sponsored by the Ministério da Ciência, Tecnologia e Inovação (MCTI, Ministry of Science, Technology, and Innovation) and by the Museu da Vida/Casa de Oswaldo Cruz/Fundação Oswaldo Cruz (Museum of Life/House of Oswaldo Cruz/Oswaldo Cruz Foundation), we demonstrate the limitations of the hypothesis that underpins many projects to popularize and teach science, that is, that citizens who are more informed - and more 'literate' in S\& $\mathrm{T}^{1}$ display more positive or more optimistic attitudes toward S\&T.

We begin by analyzing the relation between a respondent's stated interest in S\&T and stated level of information about the topic, and we show that the majority of those who say they are interested in S\&T do not claim to seek out much information on them. Secondly, we explore the relationship between information, educational level, and attitudes. As we will see, seeking out information on the topic (measured by the respondent's statements concerning his or her possession of information; access to television, radio, and internet programs on the topic; and knowledge of the name of a Brazilian scientist or scientific institution, in addition to level of formal education) is not generally associated with a more optimistic attitude but with a more complex and, in some aspects, more critical view. The data refute the simplistic hypothesis that being more informed, or having a higher educational level, means that S\&T is more accepted or seen in a more positive light. We must reconsider this notion if we want to work for more efficacious and better-quality public policies, teaching practices, and popularization initiatives.

In the first section, we examine the international panorama of research on the public perception of S\&T, its history, and its current relevance. We also offer a review of the global debate on the relation between knowledge and attitudes. In the second section, we analyze data from the recent nationwide survey conducted by the MCTI and Museu da Vida, which charts Brazilian citizens' interest in S\&T topics and their possession of information on these subjects. In the third section, we investigate the relation between information and attitudes toward these topics in Brazil today. Our understanding of information on S\&T topics in the context of this research will be explained further on. In the final section, we highlight the most relevant outcomes of our analyses and their implications for future research.

\section{Research on the public perception of science and the deficit model}

After the Second World War, in tandem with the emergence of specific S\&T policies in many developed nations (Stokes, 2005), scientists, educators, and politicians began to pay growing 
attention to, and more concern about, the role of S\&T in society and the dissemination and acceptance of the scientific culture among the public. Scientists and politicians found themselves forced to critically re-think the role of science and its public image in light of the crucial part that scientific knowledge has played in developing technology used in war - like radar, submarines, rockets, nuclear weapons, and computers - and also in light of public reaction to the bombings of Hiroshima and Nagasaki.

In the United States, for example, the creation of the National Science Foundation (NSF) in 1950 and of the National Aeronautics and Space Administration (NASA) the following decade accompanied an upsurge in debates about the social implications of science as well as the establishment of science education and popularization programs meant to strengthen public admiration and respect for national science. At the close of the 1950s, the Soviet Union's launching of the first artificial satellite in history, Sputnik, shocked U.S. public opinion and led the government there to encourage development of the NSF, support science education programs (one billion dollars were spent over the subsequent two decades), and conduct public opinion surveys about S\&T (Mead, Metraux, 1957; Withey, 1959).

A few years later, the impact caused by the student, feminist, and environmentalist movements, along with public concern and opposition to the growing environmental and social problems caused by industrialization, sparked a new wave of initiatives in S\&T popularization and education, aimed at renewing and rebuilding public support and trust in relation to S\&T (Castelfranchi, Pitrelli, 2007).

In 1979, the NSF proposed that a nationwide survey on the public perception of S\&T be conducted in the United States; since then, the poll has been repeated periodically. In the mid1980s, the Public Understanding of Science (PUS) movement appeared in Europe, following the publication of a report commissioned by the U.K.'s Royal Society (Bodmer, 1985). The movement spurred a wave of activities to foment science communication and education as well as research on the relationship between science and society (OECD, 1997a, 1997b; Durant, Evans, Thomas, 1989; Bauer, Durant, Evans, 1994). It was in this context, starting in the 1990s, that the European Commission began doing opinion polls on S\&T in general (EC, 1993, 2001, 2005) and on specific S\&T topics, like information technology (EC, 1997) and biotechnology (EC, 1991, 1997, 2000). Soon after, a number of countries undertook surveys on the public perception of science, such as India, China, and Japan (Polino, Castelfranchi, 2012; Bauer, Allum, Miller, 2007).

It has only been more recently that research into public opinion toward S\&T has garnered greater academic and political attention in Latin America. Some countries conducted nationwide polls on public perception, especially as of the 1990s, such as Colombia (Colombia, 2004), Panama (Panamá, 2001), Mexico (México, 1999, 2003), and Argentina (Argentina, 2003, 2007). Brazil fits in here as well; to date it has done three nationwide surveys in the area, the first in 1987 (CNPq/Gallup, 1987) and the second and third in 2006 and 2010 (Brasil, 2007, 2010). ${ }^{2}$

A portion of these surveys was guided by the idea that the absence of technological and scientific knowledge - which affects most people in all countries - was tied to the poor quality of the public debate on S\&T and to citizens' decreased ability to make informed decisions, something that would have serious implications in the realm of public health, politics, 
industry, and economic development. In other words, the public's knowledge deficit would need to be overcome in order to boost public participation and confidence in science and technology. For some famous scientists and science educators, such as Carl Sagan (1996), scientific illiteracy was linked to a trend to believe in pseudosciences or even to feel hostility toward science, that is, 'anti-science.'

The findings from the first surveys underscored the fact that people lacked basic knowledge of science and scientific methods; across all countries, a large share of those interviewed were "scientific illiterates" (Miller, 1983; 1998; Bodmer, 1985). The upshot of this was to reinforce an explicit or implicit way of viewing science communication and education, later labeled the 'deficit model,' since it stresses the public's deficit of scientific knowledge (Miller, 1998; Castelfranchi, 2002; Allum, Boy, Bauer, 2002; Irwin, Wynne, 1996; Sturgis, Allum, 2004); it has also been called the linear transmission model (Hilgartner, 1990).

In this model, which has guided a good share of the approaches to science journalism and the popularization of S\&T, science is thought of as lying somewhat outside the rest of society and autonomous from it. Bearing a curious kinship with phenomena that were identified and criticized by Paulo Freire in general education, in this model the public is seen as a homogenous, passive mass characterized by cognitive and informational deficits that must be remedied through a kind of transmission process, rather like administering 'knowledge pills'. The communication process is viewed as essentially unidirectional, linear, and top-down, from complex to simple, from one who knows to many who do not, and from one who produces content to others who are a scientific blank slate. Accordingly, communicating S\&T to a 'lay public' constitutes an exercise in simplification, in which the journey from science to a person's mind results in the sacrifice or loss of much information, either because the conveyor of the information trivializes it or because the recipient of the information only understands it in part, due to his or her cultural shortcomings.

In summarizing the history of these early years in the solidification of the field of PUS, Pardo and Calvo (2004, p.204) observed:

In less than a decade the core research program of the PUS field had found its definition, including as an essential and supposedly self-evident element ... the idea that ambivalence or resistance toward progress and scientific rationality flow from prejudices and anxieties tied in with ideological constructs and traditional beliefs, ones that would supposedly fade away under the influence of material progress and ... the spread of knowledge ... That people's attitudes (views, feelings, expectations) to science depend on their respective levels of scientific literacy would become a central tenet of the PUS field.

Specifically, Evans and Durant (1995) quantitatively formulated and empirically tested the hypothesis that 'positive attitudes' toward science (measured through agreement with a series of statements about its benefits and importance) would be linearly dependent upon the variable 'knowledge', defined and measured by means of a numerical scale that tallies up the precise answers to a battery of questions.

However, the empirical data called this comfortable hypothesis into question. The data from Evans and Durant (1995) seemed to point to a hazy, non-linear relation that did not tie knowledge so much to attitudes in general but rather to a differentiation between attitudes: 
the greater a respondent's degree of scientific knowledge, the greater the apparent diversity of attitudes toward different facets of S\&T. In cases where research in a specific area was associated with a moral dilemma (e.g., human embryo research), the correlation was very weak or even negative, with respondents who had a greater knowledge of science tending to express a more critical view.

Subsequent research confirmed this problem and heated up the debate. On the one hand, most surveys detected a positive statistical relationship between agreement with certain statements (e.g., the sun rotates around the earth, plants produce oxygen, etc.) and the expression of generally more positive attitudes about S\&T on the whole (see, for example, Allum et al., 2008). Comparing data from polls conducted in Europe, the United States, and Japan, Miller, Pardo, and Niwa (1997) concluded that there was a relation between knowledge and positive attitudes and that this relation did not vary substantially between the cultures or socioeconomic systems under study. On the other hand, as factual knowledge of S\&T grew, attitudes toward some technology were more critical or cautious.

Transgenics provide a well-studied example of this phenomenon. Although some biologists and biotechnologists tend to associate rejection or criticism of the use of transgenic seeds with 'ignorance,' 'irrational' fear, or 'ideologies,' data have indicated something more complex, and more interesting. In the United States, evidence showed that a greater knowledge of genetics was positively associated with its acceptance (Priest, 2001). Yet Martin and Tait (1992) observed that a high level of knowledge about S\&T was also associated with both positive and negative attitudes toward agricultural biotechnology. In Europe, the situation was even more complex. Durant, Bauer, and Gaskell (1998) studied biotechnology in the public sphere using data gathered by Eurobarometer. Data analysis revealed only a modest correlation between support and knowledge; whether or not someone was optimistic or pessimistic about biotechnology's contribution to his or her life was not tied to a person's knowledge. Greater knowledge was not associated so much with positive attitudes but rather with whether the respondent had a well-defined position on biotechnology.

Studies by Gaskell and Bauer (2001) indicated that people with less knowledge about topics in biotechnology tended to feel that medical application of biotechnology (so-called red biotechnology) presents a risk to society. But when the topic was 'green' biotechnology (i.e., applied to agriculture), no such relation appeared; there was no association between a negative perception of the use of genetically modified organisms in agriculture and a lower degree of scientific literacy.

The relation between interest, knowledge, and attitudes became one of the most controversial and hotly debated questions because of the findings from major international surveys on perceptions of S\&T. Many authors lodged trenchant criticisms of the way that knowledge is measured (see, for example, Pardo, Calvo, 2002, 2004; Godin, Gingras, 2000; Albornoz et al., 2003; Roth, Lee, 2002). The questions about notions, facts, and processes in science were poorly formulated and analyzed and reflected a bias tied to the deficit model (where a knowledge deficit in S\&T leads to fear and a pessimistic stance toward S\&T) that failed to account for cognitive aspects of PUS. 'Science literacy' was measured simplistically, using a series of mostly closed-ended questions that entailed notions that were of import to some researchers but that were not always truly connected with someone's knowledge or 
understanding, since meanings and significances depended upon the respondent's historical moment and culture. ${ }^{3}$

Furthermore, there were problems with the statistical coherence of the items used in questionnaires. In the case of some questions, the number of correct responses rose in accordance with the respondent's educational level - as was expected. But in others, the distribution of right and wrong answers did not vary with the respondent's educational level or accessing of information. Still other questions seemed to elicit responses that had more to do with people's political leanings or religious affiliation than with their scientific knowledge.

In one interesting study, Bauer, Durant, and Evans (1994) analyzed data from 11 European countries and reached the following hypothesis: the relation between having knowledge about S\&T and having a positive attitude toward them depended on the socioeconomic development of each country. For these authors, societies that are in the phase of strong industrial development but have not yet reached the post-industrial phase tend to display cultural views that value S\&T and that associate S\&T with the idea of economic progress and social and moral emancipation. In these countries, the citizens who are interested in science and know more about it also tend to be those who display a more optimistic, idealized view of technological progress and the liberating role of science.

In countries that have already entered the post-industrial phase, that display high levels of gross domestic product (GDP) per capita, and where S\&T systems have already developed, the complexity of the social and environmental impacts of industrialization have been perceived, and views of science and technology are more diverse and skeptical; there is a mistrust of S\&T, their role in society is questioned, and attitudes are less monolithic and idealized. People tend to be neither optimistic nor pessimistic on the whole about S\&T but want to understand and examine matters on a case by case basis; differentiated attitudes emerge concerning different aspects of research and technological applications. In any case, a paradox was identified, which Bauer and colleagues called the "knowledge-ignorance paradox" (Bauer, Durant, Evans, 1994): when public understanding of science spreads out and scientific knowledge disseminates, science becomes more tricky to public (Gaskell, Bauer, 2001).

The debate is still open. But we can state, in the words of Allum et al. (2008, p.39-40), that "the empirical research ... has shown that a simple, positive, linear relationship between attitudes and knowledge about science ... is an over-simplification".

In the next section, we bring this discussion into the present through an examination of the opinions and attitudes of Brazilians.

\section{Brazilians' interest in S\&T and their information on the topic}

In 2010, the MCTI, through its Departamento de Popularização e Difusão da C\&T (Department of S\&T Popularization and Outreach), and the Museu da Vida, which is part of the Casa de Oswaldo Cruz/Fiocruz, with the collaboration of Unesco, carried out a nationwide survey on the public perception of S\&T (Brasil, 2010). ${ }^{4}$ The study's target public comprised Brazilians aged 16 and above, and it was based on a structured questionnaire consisting of 101 open-ended or closed-ended questions. From June 23 to July 6, 2010, 2,016 interviews were conducted, based on a representative sample of Brazilians stratified according to gender, 
age, educational level, income, and region of residence. ${ }^{5}$ The margin of error for parameter estimation was $2.18 \%$, at a $5 \%$ significance level, for a confidence interval of $95 \%$.

The survey provided a wealth of data on the Brazilian public's accessing of information on S\&T and their understanding of science communication, as well as on their behaviors, habits, and attitudes toward S\&T. In this section, we undertake an in-depth analysis of the relation between interest and degree of information and their association with variables like education, income, and place of residence. We describe the variables that we used to measure a respondent's degree of information on S\&T. These formed our analytical focus in examining the relation between the information that Brazilians have on S\&T and their perceptions of them.

\section{Relation between interest in S\&T and information on the topic}

Despite the oft-heard complaint that the population at large has little or no interest in scientific topics - as proclaimed by the scientific and educational communities as well as by the media - Brazilians stated that they were quite interested in science and technology. The 2010 study (Brasil, 2010) contains specific questions on interest and level of information about a number of topics, including S\&T (i.e., "I am going to read a list of topics. What is your degree of interest in each of them?" and "How much do you inform yourself about the following topics?")

Two specific questions measured the degree of information on S\&T research in Brazil: "Do you know of any institution devoted to scientific research in Brazil?" and "Can you recall the name of any important Brazilian scientist?" In addition, a battery of questions allowed us to measure habits in the consumption of scientific information: "For the following questions, how often (very often/not very often/never/don't know or no response) do you: Watch television programs about science and technology?; Listen to radio programs on science and technology?; Read about science and technology in newspapers?; Read about science and technology in magazines or journals?; Read about science and technology in books?; Read about science and technology on the internet?; Talk with your friends about science and technology?"

Using the responses to these questions, we created four test variables to ascertain how these impact Brazilians' attitudes and perceptions of S\&T: (a) stated interest in S\&T; (b) stated information on S\&T; (c) claiming to know the name of a scientific institution or a scientist (knowing S\&T); and (d) index of consumption of scientific information (Icic). ${ }^{6}$ The measurement of these variables revealed important findings. As shown in Graph 1, respondents declared a high level of interest in S\&T subjects: 65\% said they were very interested or interested. This level is comparable with respondents' stated interest in sports (62\% interested or very interested) and the economy (71\% interested or very interested) and is higher than their stated interest in politics, art and culture, and fashion, losing only to medicine, the environment, and religion.

When we analyzed the relation between interest and information on S\&T (Graph 2), we observed that most (86\%) of those who said they were interested or very interested also stated that they were informed or very informed. However, it should be pointed out that this relatively high stated interest does not necessarily mean that the respondent knew the 
name of a scientific institute in Brazil or a Brazilian scientist: $71 \%$ of those who were very interested in S\&T did not claim to know the name of any research institution in Brazil, and $82 \%$ of them said they did not know the name of any Brazilian scientist. The relation between interest and accessing information on S\&T needs to be problematized. Although claimed knowledge of scientists or institutions increases on average as the level of interest does (29\% of the respondents who were very interested said they knew of an institution, compared to $2.5 \%$ of those who had no interest), claimed knowledge was still extremely low in all groups.

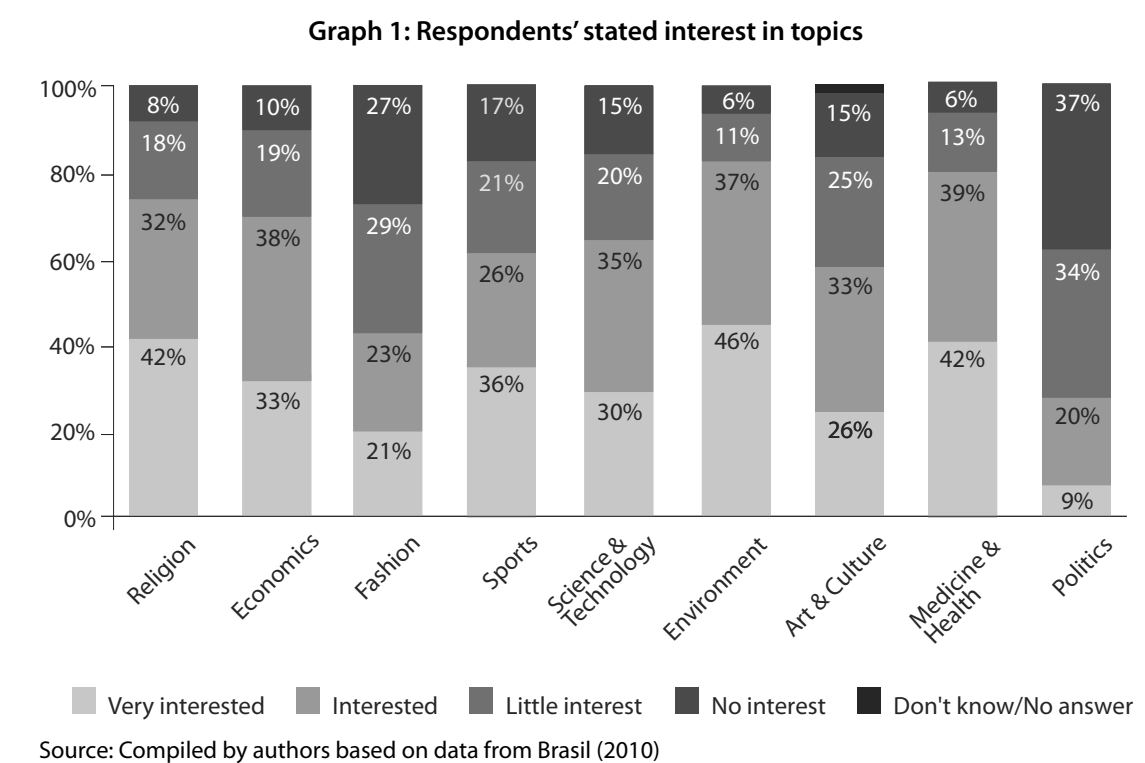

Graph 2: Respondents' stated interest in S\&T versus respondents' stated level of information

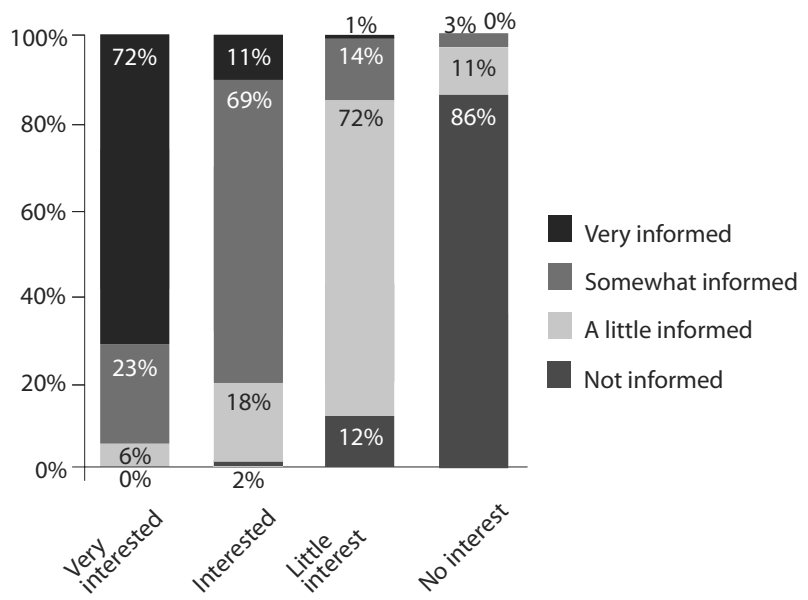

Source: Compiled by authors based on data from Brasil (2010) 
What is interesting about this finding is that a lack of sincerity is not enough to account for it. Some respondents may indeed exaggerate their interest in S\&T because they do not want to disappoint the interviewer or admit that they pay little attention to topics that are considered relevant. Nevertheless, various indicators show that a significant share of the public may be truly interested in S\&T but still does not actively seek information or is unable to do so. For example, $29 \%$ of those who said they were very interested admitted that they were somewhat or a little informed; among those who said they were interested, only $11 \%$ considered themselves very informed, compared to $20 \%$ who stated they were a little or not informed; if these people were exaggerating their interest, they would not state that they only had scant information on the subject matter.

Analogously, when we examined the data on the consumption of scientific information, we discovered that $10 \%$ of those who said they were very interested in S\&T and $21 \%$ of those who said they were interested admitted that they never watch television programs on the topic.

As we saw in our earlier discussion, there is no consensus about how to measure scientific literacy and knowledge of S\&T. The team that planned the MCTI survey took into account the broad international debate concerning the formulation of questions based on factual notions and also the limitation of intentions to measure 'scientific knowledge' through this type of question; accordingly, they decided not to include questions based on specific notions of science. The study instead relied only on the two questions listed earlier (about knowing the name of a research institution in Brazil of a Brazilian scientist), plus educational level, as indirect indicators of whether a respondent had any basic information on scientific research in Brazil.

We are aware that these questions do not suffice to ascertain a person's degree of knowledge of S\&T topics; instead, in conjunction with the questions about the consumption of scientific information in the media and with educational level, we feel that they simply serve as base indicators of informational habits and of contact with news and information on the S\&T produced in Brazil. Although it is possible to know the name of the Fundação Oswaldo Cruz or Universidade de São Paulo or of the scientist Carlos Chagas without knowing hardly anything about biology or medicine, we believe that the opposite is unlikely: someone who has information about research done in Brazil can likely name at least one research institution. In the present study, we did not measure individuals' knowledge of S\&T but proposed a broader measurement of a respondent's habit of accessing information on S\&T. This measurement is found in the four variables mentioned earlier, plus educational level. Based on these measurements, we tested the hypothesis that more information leads to a more positive attitude toward S\&T.

To this end, we first endeavored to ascertain whether more information leads to a more optimistic view of S\&T. We classified respondents' views as optimistic or pessimistic based on a survey question about his or her view of the consequences of S\&T: "Do science and technology cause humanity more harm or offer it more benefits?" The possible responses were: "Only benefits" (39\%); "More benefits than harm" (43\%); "Both benefits and harm" (14\%); "More harm than benefits" (3\%); "Only harm" (1\%). 
We used a logistic regression model to investigate whether optimism about the benefits of S\&T is related to information and interest (i.e., whether it is controlled by other variables, like gender, age, income, and place of residence). This is the most appropriate technique when analyzing data in which the qualitative dependent variable comprises two categories, that is, when it is a binary variable. We analyzed optimism by constructing a dependent variable whose value was 1 when the respondent agreed with either the statement that science brings more benefits than harm or that it brings only benefits, and 0 in all other cases (more harm, only harm, both benefits and harm). In addition to optimistic outlook, other responses related to Brazilian attitudes toward S\&T were analyzed using logistic regression.

Our proposed regression model is:

$\log [\mathrm{p}(\mathrm{y}=\mathrm{j} \mid \mathrm{x}=\mathrm{i}) / \mathrm{p}(\mathrm{y}=1 \mid \mathrm{x}=\mathrm{i})]=\beta 0+\beta_{1} \mathrm{X}_{1}+\ldots+\beta_{\mathrm{K}} \mathrm{X}_{\mathrm{K}}+\varepsilon$

In logistic regression, the logarithm of the ratio of probabilities is linearly related to $X_{k^{\prime}}$ where:

$\mathrm{P}=$ probability that $\mathrm{Yi}=1$ (that the event will occur);

$1-\mathrm{P}=$ probability that $\mathrm{Yi}=0$ (that the event will not occur);

$\beta_{0}=$ probability that the event will occur when all $\mathrm{X}=0$ (intercept);

$\beta_{\mathrm{k}}=$ variation in the effect of the explanatory variable on the probability that the event will occur (slope);

$\mathrm{X}_{\mathrm{k}}=$ independent variables;

$\varepsilon=$ stochastic error.

In the logistic models used in the present article:

$\mathrm{p}(\mathrm{y}=\mathrm{j} \mid \mathrm{x}=\mathrm{i} / \mathrm{p}(\mathrm{y}=1 \mid \mathrm{x}=\mathrm{i})$ is the probability that the respondent (i) will fall into the category (j) of being optimistic about S\&T (in agreement with statements about S\&T), as compared to falling into the category of not being optimistic (not in agreement with the reference category); $\beta_{0}$ is the probability that the respondent (i) will fall into the category (j) of being optimistic about S\&T (in agreement with statements about S\&T), as compared to falling into the category of not being optimistic (not in agreement with the reference categories), when all $\mathrm{X}$ (independent variables) are zero;

$\beta_{1}$ to $\beta_{\mathrm{k}}$ are the coefficients for the independent variables;

$\mathrm{X}_{1}$ to $\mathrm{X}_{\mathrm{k}}$ are the independent variables, to wit: test variables (educational level, stated interest, stated information, claiming to know a Brazilian scientist or institution; Icic) and control variables (gender, age bracket, income bracket, region, and size of city) (see Table 1).

Table 1: Variables used in the logistic regression model

\begin{tabular}{|l|l|l|}
\hline \multicolumn{2}{|c|}{ Dependent variables } \\
\hline Variable & Type & Description \\
\hline Optimistic & Binary & $\begin{array}{l}\text { Optimistic }=1 \\
\text { Not optimistic }=0\end{array}$ \\
\hline Scientific research is not vital to the development of industry & Binary & $\begin{array}{l}\text { Agree }=1 \\
\text { Do not agree }=0\end{array}$ \\
\hline $\begin{array}{l}\text { Scientists must make public the risks associated with scientific and } \\
\text { technological development }\end{array}$ & Binary & $\begin{array}{l}\text { Agree }=1 \\
\text { Do not agree }=0\end{array}$ \\
\hline
\end{tabular}


Table 1 (cont.): Variables used in the logistic regression model

\begin{tabular}{|c|c|c|}
\hline \multicolumn{3}{|l|}{ Dependent variables } \\
\hline $\begin{array}{l}\text { The public should be heard when it comes to major decisions about the } \\
\text { direction of science and technology }\end{array}$ & Binary & $\begin{array}{l}\text { Agree }=1 \\
\text { Do not agree }=0\end{array}$ \\
\hline $\begin{array}{l}\text { The use of computers and industrial automation will create more jobs than } \\
\text { they will eliminate }\end{array}$ & Binary & $\begin{array}{l}\text { Agree }=1 \\
\text { Do not agree }=0\end{array}$ \\
\hline Our society depends greatly on science and not enough on faith & Binary & $\begin{array}{l}\text { Agree }=1 \\
\text { Do not agree }=0\end{array}$ \\
\hline Government leaders should follow the guidance of scientists & Binary & $\begin{array}{l}\text { Agree }=1 \\
\text { Do not agree }=0\end{array}$ \\
\hline Because of knowledge, scientists have power that makes them dangerous & Binary & $\begin{array}{l}\text { Agree }=1 \\
\text { Do not agree }=0\end{array}$ \\
\hline $\begin{array}{l}\text { Technological applications that have a major impact can cause } \\
\text { environmental catastrophes }\end{array}$ & Binary & $\begin{array}{l}\text { Agree }=1 \\
\text { Do not agree }=0\end{array}$ \\
\hline $\begin{array}{l}\text { A scientific discovery in and of itself is neither good nor bad; what matters } \\
\text { is how it is used }\end{array}$ & Binary & $\begin{array}{l}\text { Agree }=1 \\
\text { Do not agree }=0\end{array}$ \\
\hline Scientists should have broad freedom to do the research they want & Binary & $\begin{array}{l}\text { Agree }=1 \\
\text { Do not agree }=0\end{array}$ \\
\hline \multicolumn{3}{|l|}{ Independent test variables } \\
\hline \multicolumn{3}{|l|}{ Educational level } \\
\hline Elementary $\left(\mathrm{X}_{1}\right)$ & Binary & $\begin{array}{l}\text { Elementary }=1 \\
\text { College }=0 \text { (reference } \\
\text { category) }\end{array}$ \\
\hline High school $\left(X_{2}\right)$ & Binary & $\begin{array}{l}\text { High school }=1 \\
\text { College }=0 \text { (reference } \\
\text { category) }\end{array}$ \\
\hline Stated interest $\left(\mathrm{X}_{3}\right)$ & Binary & $\begin{array}{l}\text { Interested and very } \\
\text { interested }=1 \\
\text { Little or no interest }=0\end{array}$ \\
\hline Stated information $\left(\mathrm{X}_{4}\right)$ & Binary & $\begin{array}{l}\text { Informed and very } \\
\text { informed }=1 \\
\text { Little or not informed } \\
=0\end{array}$ \\
\hline Knowing the name of a scientific institution or scientist $\left(X_{5}\right)$ & Binary & $\begin{array}{l}\text { Know }=1 \\
\text { Do not know }=0\end{array}$ \\
\hline Consumption of information on S\&T $\left(\mathrm{X}_{6}\right)$ & Discrete & $\begin{array}{l}\text { Consumption indicator } \\
\text { (varies from } 1 \text { to } 4 \text { ) }\end{array}$ \\
\hline \multicolumn{3}{|l|}{ Independent control variables } \\
\hline Gender $\left(\mathbf{X}_{7}\right)$ & Binary & $\begin{array}{l}\text { Man }=1 \\
\text { Woman }=0\end{array}$ \\
\hline \multicolumn{3}{|l|}{ Region } \\
\hline South $\left(X_{8}\right)$ & Binary & $\begin{array}{l}\text { Southern Brazil = } 1 \\
\text { Northern/Northeastern } \\
\text { and Central-Western } \\
\text { Brazil = } 0 \text { (reference } \\
\text { category) }\end{array}$ \\
\hline
\end{tabular}


Table 1 (cont.): Variables used in the logistic regression model

\begin{tabular}{|c|c|c|}
\hline \multicolumn{3}{|c|}{ Independent control variables } \\
\hline Southeast $\left(X_{9}\right)$ & Binary & $\begin{array}{l}\text { Southeastern Brazil = } 1 \\
\text { Northern/Northeastern } \\
\text { and Central-Western } \\
\text { Brazil }=0\end{array}$ \\
\hline \multicolumn{3}{|l|}{ Size of city } \\
\hline Small $\left(\mathrm{X}_{10}\right)$ & Binary & $\begin{array}{l}\text { Small }=1 \\
\text { Large }=0 \text { (reference } \\
\text { category) }\end{array}$ \\
\hline Medium $\left(\mathrm{X}_{11}\right)$ & Binary & $\begin{array}{l}\text { Medium }=1 \\
\text { Large }=0 \text { (reference } \\
\text { category) }\end{array}$ \\
\hline Income $\left(X_{12}\right)$ & Discrete & $\begin{array}{l}\text { Income brackets from } \\
1 \text { to } 6\end{array}$ \\
\hline Age bracket $\left(X_{13}\right)$ & Discrete & $\begin{array}{l}\text { Age brackets from } 1 \\
\text { to } 6\end{array}$ \\
\hline
\end{tabular}

Source: Compiled by authors

Following the above presentation of our test variables and dependent variables (responses), we will now focus on the central concern of the present study: Is there a positive association between level of information and positive, optimistic attitudes toward S\&T?

\section{Discussing the 'paradox': the relation between information and attitudes in Brazil}

Brazilian data reveal an interesting feature of the relation between interest, information, and attitudes. We found that many of the attitudes toward S\&T as measured by the Brazilian survey display no significant relation to interest, educational level, or level of information. While multiple factors influenced attitudes, each one carried a relatively small weight. In some cases, variations in attitudes toward S\&T were affected more by the region or city in which the respondent lived than by his or her accessing of information or degree of education. Yet some facets of S\&T are viewed more optimistically by people with a higher educational level or more information on Brazilian science. In regard to other relevant aspects, however, groups with more education or information seem to display a more differentiated attitude, which varies as a function of diverse aspects of S\&T. When asked whether S\&T play a positive role in society and if the associated risks are fewer than the benefits, people who accessed information more tended to respond "it depends".

The first logistic regression model, on the variable optimism, yielded a finding that merits attention: the notion that a higher educational level and accessing information more, or a higher sociocultural and economic level, correspond to greater confidence in the benefits of S\&T needs to be problematized.

Table $1^{7}$ shows the results from the first regression. The model that analyzes the dependence of the variable optimism as a function of the independent variables described earlier (test 
and control) accounts for less than $4 \%$ of the variation (Nagelkerke $=0.04$ ). In other words, the variables related to the respondent's profile (socioeconomic and demographic), region, size of city, and interest in S\&T and information about them do not allow us to predict that his or her outlook will be optimistic, except at a minimal level; thus, these variables are not determinant in accounting for Brazilians' views of the benefits of S\&T or harm done by them.

The model does, however, detect some significant statistical relations and allows us to refute simplistic assumptions about the role that information plays in shaping attitudes. In the first place, as income climbed, the chance that a respondent would say she or he was optimistic dropped. Each one-point bump upward in income bracket yielded a $14 \%$ decrease in the probability that a respondent would have an optimistic outlook toward S\&T. In the second place, women seemed more cautious about the benefits of S\&T; male respondents were $29 \%$ more likely to have an optimistic outlook. The same was true of age, with older respondents being more cautious; for each one-point rise in age bracket, the chances of a respondent being optimistic fell $8 \%$. In regard to region of residence, the only significant effect was seen for Southeastern Brazil when compared to the whole of the North, Northeast, and Central-West, since the odds that a respondent would be optimistic about the topic jumped $105 \%$ when he or she resided in the Southeast. Lastly, in regard to test variables - and perhaps this is the most relevant finding - a higher educational level, stated level of interest or of information, and accessing programs on S\&T played no significant statistical role in accounting for variations in optimism or pessimism about the topic. The only variable that had statistical significance (at the level of 5\%) in explaining these variations was whether the respondent knew the name of a Brazilian scientist or scientific institution, which had a positive impact (40\%) on the identification of an optimistic outlook. In other words, someone who said he or she knew the name of a Brazilian scientist or scientific institution was $40 \%$ more likely to be optimistic about S\&T than someone who said he or she did not.

It therefore cannot be stated that level of information is an important factor in accounting for people's optimism about the consequences of S\&T. Having little information was not associated with pessimism. People who had a higher educational level, or who said they were interested in S\&T or accessed information on the topic, were just as likely to be optimistic as pessimistic about the benefits of S\&T.

Table 2: Logistic regression predictors for an optimistic outlook toward S\&T

\begin{tabular}{|l|l|l|}
\hline & \multicolumn{2}{|l|}{ Optimistic } \\
\hline & Exp(B) & $\%$ probability \\
\hline Gender & $1,29^{*}$ & $\uparrow 29 \%$ \\
\hline Southeastern Brazil & $2,05^{* *}$ & $\uparrow 105 \%$ \\
\hline Income bracket & $0,86^{*}$ & $\downarrow 14 \%$ \\
\hline Age bracket & $0,92^{*}$ & $\downarrow 8 \%$ \\
\hline Knowing institution or scientist & $1,40^{*}$ & $\uparrow 40 \%$ \\
\hline Nagelkerke & 0,044 & \\
\hline
\end{tabular}

* Statistically significant at $5 \%$; * Statistically significant at $1 \%$ Source: Compiled by authors based on data from Brasil (2010) 
Since our study shows the inaccuracy of the hypothesis that educational level or accessing information is generally linked to greater optimism, it is necessary to undertake an in-depth analysis that will tease out the relations between educational level, information, and more specific attitudes toward the social and economic impact of S\&T, their political governance, and their risks. For this purpose, we analyzed the survey questions that measure attitudes about different aspects of S\&T. We once again reached the conclusion that most attitudes cannot be explained by educational level, accessing information, or a respondent's stated interest in S\&T. From the perspective of the logistic regression model, only three of all survey questions about attitudes displayed any degree of consistent influence from socioeconomic factors or the respondent's level of interest or information; these were: "Scientific research is not vital to the development of industry"; "Scientists must make public the risks associated with scientific and technological development"; and "The public should be heard when it comes to major decisions about the direction of science and technology." Although the explanatory weight of each was low (14\%, 13\%, and $11 \%)$, the detected associations were significant, as we show in the next section.

"Scientific research is not vital to the development of industry"

Although the majority of Brazilians disagree with this statement, and although the logistic regression model accounts for only a small part of the variations in responses, some statistically significant associations were identified between this attitude and certain variables: (a) the probability that the respondent would agree with the statement that scientific research is "not" vital to the development of industry rose for people who live in Southern Brazil (compared to residents of the North, Northeast, and Central-West), those who have a lower income, or those who do not claim to know the name of a Brazilian scientist or scientific institution; (b) the probability of disagreeing with the same statement (i.e., of considering science vital to industry) climbed among people who live in the Southeast, who have a higher income, or who claimed to know the name of a Brazilian institution or scientist.

At a more in-depth level, we can affirm that living in Southern Brazil, compared to living in the North, Northeast, or Central-West, was associated with a $151 \%$ hike in the chances that the respondent would agree with the statement that "scientific research is "not" vital to the development of industry" (see Table 3). The opposite was the case for residents of

Table 3: Logistic regression predictors for attitudes toward S\&T

\begin{tabular}{|l|l|l|}
\hline & \multicolumn{2}{|l|}{$\begin{array}{l}\text { Scientific research is not vital to } \\
\text { the development of industry }\end{array}$} \\
\hline & Exp(B) & $\%$ probability \\
\hline Southern Brazil & $2,511^{* *}$ & $\uparrow 151 \%$ \\
\hline Southeastern Brazil & $0,593^{* *}$ & $\downarrow 41 \%$ \\
\hline Income bracket & $0,847^{* *}$ & $\downarrow 16 \%$ \\
\hline $\begin{array}{l}\text { Knowing name of scientific } \\
\text { institution or scientist }\end{array}$ & $0,508^{* *}$ & $\downarrow 50 \%$ \\
\hline Nagelkerke & \multicolumn{2}{|c|}{0,138} \\
\hline
\end{tabular}

* Statistically significant at $5 \%$; ** Statistically significant at $1 \%$

Source: Compiled by authors based on data from Brasil (2010) 
Southeastern Brazil, who were 41\% less likely to agree with the statement than were people living in the North, Northeast, or Central-West. People who claimed to know the name of a Brazilian scientist or research institution were 50\% less likely to agree with the statement than those who did not claim to know this. As to income bracket, a one-point increase reduced a respondent's chances of agreeing with this statement by $16 \%$.

"Scientists must make public the risks associated with scientific and technological development"

In this case, an explanatory explanation was found only for Southeastern Brazil, which was statistically significant at the $1 \%$ level. Interest, information, gender, educational level, and income did not have any significant impact on the response to this question. Living in Southeastern Brazil, compared with living in the other reference regions, boosted a respondent's chances of agreeing with this statement by $591 \%$.

"The public should be heard when it comes to major decisions about the direction of science and technology"

'Region' was also the explanatory variable in this case, at a 1\% level of statistical significance. Those residing in Southern Brazil tended to disagree about the need to hear from the public at large (see Table 4); the chances of someone there agreeing with the statement were $66 \%$ lower than for people living in the North, Northeast, or Central-West. The opposite was true of respondents from Southeastern Brazil, who were 169\% likelier to agree with the statement.

Table 4: Logistic regression predictors for attitudes toward S\&T

\begin{tabular}{|l|l|l|}
\hline & \multicolumn{2}{|l|}{$\begin{array}{l}\text { The public should be } \\
\text { heard when it comes to } \\
\text { major decisions about the } \\
\text { direction of science and } \\
\text { technology }\end{array}$} \\
\hline & Exp(B) & $\%$ probability \\
\hline Southern Brazil & $0,341^{* *}$ & $\downarrow 66 \%$ \\
\hline Southeastern Brazil & $2,69^{* *}$ & $\uparrow 169,2 \%$ \\
\hline Stated information on S\&T & $1,68^{*}$ & $\uparrow 68 \%$ \\
\hline R-square & 0,102 & \\
\hline
\end{tabular}

* Statistically significant at 5\%; ** Statistically significant at $1 \%$ Source: Compiled by authors based on data from Brasil (2010)

In addition to 'region', the variable 'stated information' proved statistically significant (at 5\%) in accounting for variations in agreement with the statement. Among people who said they were informed about S\&T, the odds of agreeing that "the public should be heard when it comes to major decisions about the direction of science and technology" increased $68 \%$ compared with those who said they were not informed.

In the case of the remaining attitude questions presented in the survey, the binary logistic models generally did not detect a significant variation that could be explained by any one 
factor. In other words, the variation between agreeing or not agreeing with the attitude statements could not be explained by the measured factors (independent variables), since more than $90 \%$ of the variation was generally not accounted for by the variables included in the models. Therefore, the test variables did not prove significant in explaining these attitudes.

Specifically, there was no statistically significant association between a respondent's information and the responses to the following statements: (a) science and technology will "not" help eliminate poverty and hunger in the world; (b) science will help cure diseases like AIDS, cancer, etc.; (c) scientists must make public the risks associated with scientific and technological development; (d) if a new technology offers benefits, it should be used even if its consequences are not well known; (e) scientists are responsible for how others use their discoveries; (f) government officials should legally force scientists to follow ethical standards.

However, some attitudes did display a weak albeit significant association with educational level or level of information, to wit: (a) the use of computers and industrial automation will create more jobs than they will eliminate; (b) our society depends greatly on science and not enough on faith; (c) government leaders should follow the guidance of scientists; (d) because of knowledge, scientists have power that makes them dangerous; (e) technological applications that have a major impact can cause environmental catastrophes; (f) a scientific discovery in and of itself is neither good nor bad; what matters is how it is used; (g) scientists should have broad freedom to do the research they want. The results of predictors of association between interest, educational level, or information and the statements about attitudes toward S\&T are shown in Table 5 . We have only included predictors that were significant at a maximum level of 5\%.

As we examine these statements, we can see that: (a) a respondent's stated interest is not associated with the measured attitudes; (b) educational level is only statistically and positively significant for the statement "because of knowledge, scientists have power that makes them dangerous"; (c) stated information has a positive impact on the chances of someone agreeing with the statements "the use of computers and industrial automation will create more jobs than they will eliminate" and "government leaders should follow the guidance of scientists"; (d) for those who said they knew the name of a Brazilian scientific institution or scientist, chances are higher that they will agree with the above statements and thereby display a more critical view of science, since they tend to agree both with statements that couch science as beneficial (e.g., "government leaders should follow the guidance of scientists") and with statements that see science as a risk for humanity (e.g., "because of knowledge, scientists have power that makes them dangerous").

In other words, the fact that someone claimed to know the name of a Brazilian scientist or research institution had a different effect on different facets of esteem for science and technology. People who said that they knew the name of an institution and a scientist were more inclined to emphasize the centrality of S\&T in contemporary life as well as their power. However, this emphasis applies as much to aspects perceived as positive (e.g., helping industrial development) as to those seen as negative (e.g., scientists have power that makes them dangerous; environmental catastrophes). It is not by chance that a generally optimistic view (science does good or causes more good) was not associated in any significant way with having more information or a high educational level, nor was it associated with a pessimistic 
view. Lastly, the consumption of information on S\&T likewise was not statistically significant in explaining all of the proposed statements. Only three statements were influenced by this variable. The findings showed an inversely proportionate relation between the dependent and independent variables, that is, the more a respondent consumed information on S\&T, the lower his or her positive emphasis of the centrality of S\&T in contemporary life.

Table 5: Information indicators as predictors of the probability that a respondent will agree with statements involving attitudes toward S\&T

\begin{tabular}{|c|c|c|c|c|c|c|}
\hline Statement & & $\begin{array}{l}\text { Elementary } \\
\text { education }\end{array}$ & $\begin{array}{l}\text { High } \\
\text { school } \\
\text { education }\end{array}$ & $\begin{array}{l}\text { Stated } \\
\text { information }\end{array}$ & $\begin{array}{l}\text { Knowing } \\
\text { name of } \\
\text { institution } \\
\text { or scientist }\end{array}$ & $\begin{array}{l}\text { Index of } \\
\text { consumption } \\
\text { of information } \\
\text { about S\&T }\end{array}$ \\
\hline \multirow{2}{*}{$\begin{array}{l}\text { The use of } \\
\text { computers } \\
\text { and industrial } \\
\text { automation will } \\
\text { create more jobs } \\
\text { than they will } \\
\text { eliminate }\end{array}$} & $\operatorname{Exp}(B)$ & & & 1,42 & & 0,82 \\
\hline & $\begin{array}{l}\% \\
\text { probability }\end{array}$ & & & $\uparrow 42 \%$ & & $\downarrow 18 \%$ \\
\hline \multirow{2}{*}{$\begin{array}{l}\text { Our society } \\
\text { depends greatly } \\
\text { on science and not } \\
\text { enough on faith }\end{array}$} & $\operatorname{Exp}(B)$ & & & & 1,5 & \\
\hline & $\begin{array}{l}\% \\
\text { probability }\end{array}$ & & & & $\uparrow 50 \%$ & \\
\hline \multirow{2}{*}{$\begin{array}{l}\text { Government } \\
\text { leaders should } \\
\text { follow the } \\
\text { guidance of } \\
\text { scientists }\end{array}$} & $\operatorname{Exp}(B)$ & & & $1,37^{*}$ & $1,91^{* *}$ & \\
\hline & $\begin{array}{l}\% \\
\text { probability }\end{array}$ & & & $\uparrow 37 \%$ & $\uparrow 91 \%$ & \\
\hline \multirow{2}{*}{$\begin{array}{l}\text { Because of } \\
\text { knowledge, } \\
\text { scientists have } \\
\text { power that makes } \\
\text { them dangerous }\end{array}$} & $\operatorname{Exp}(B)$ & $1,55^{*}$ & $1,74^{* *}$ & & $1,48^{* *}$ & \\
\hline & $\begin{array}{l}\% \\
\text { probability }\end{array}$ & $\uparrow 55 \%$ & $\uparrow 74 \%$ & & $\uparrow 48 \%$ & \\
\hline \multirow{2}{*}{$\begin{array}{l}\text { Technological } \\
\text { applications that } \\
\text { have a major } \\
\text { impact can cause } \\
\text { environmental } \\
\text { catastrophes }\end{array}$} & $\operatorname{Exp}(B)$ & & & & $1,71^{* *}$ & $1,23^{*}$ \\
\hline & $\begin{array}{l}\% \\
\text { probability }\end{array}$ & & & & $\uparrow 71 \%$ & $\uparrow 23 \%$ \\
\hline \multirow{2}{*}{$\begin{array}{l}\text { A scientific } \\
\text { discovery in and } \\
\text { of itself is neither } \\
\text { good nor bad; } \\
\text { what matters is } \\
\text { how it is used }\end{array}$} & $\operatorname{Exp}(B)$ & & & & $1,76^{* *}$ & $0,80^{* *}$ \\
\hline & $\begin{array}{l}\% \\
\text { probability }\end{array}$ & & & & $\uparrow 76 \%$ & $\downarrow 20 \%$ \\
\hline \multirow{2}{*}{$\begin{array}{l}\text { Scientists should } \\
\text { have broad } \\
\text { freedom to do the } \\
\text { research they want }\end{array}$} & $\operatorname{Exp}(B)$ & & & & $1,56^{* *}$ & 0,87 \\
\hline & $\begin{array}{l}\% \\
\text { probability }\end{array}$ & & & & $\uparrow 56 \%$ & $\downarrow 13 \%$ \\
\hline
\end{tabular}

* Statistically significant at 5\%; ** Statistically significant at $1 \%$ Source: Compiled by authors based on data from Brasil (2010) 


\section{Final considerations}

Contrary to the concerns often expressed by some scientists, educators, or science communicators about an alleged wave of pessimism, fear, or hostile attitudes toward science and technology, our data show that the vast majority of Brazilians display a trusting, optimistic view that generally expresses support for science. More cautious or critical attitudes appear in relation to the social implications of specific aspects of S\&T.

These attitudes are framed within the context of a belief in the relevant transformative power of S\&T - a belief shared by the overwhelming majority of the public (both optimistic and pessimistic) - and a growing demand seen in all democracies for a more participatory social debate. Analogously, in contradiction with the opinions of many intellectuals that Brazilians are ignorant because they have no interest in S\&T - the data showed that most Brazilians say they are interested in scientific topics. Our analysis showed evidence that although this stated interest may be exaggerated because the issue is socially relevant, it is real in that it is statistically associated with pertinent variables, such as to know the name of a Brazilian scientist or research institution, educational level, income, access to museums and science centers, and so on.

Our most relevant findings confirm a phenomenon that has been detected in other countries. The hypothesis that more education or more information prompts generally more positive attitudes about the role of S\&T in society was refuted by the empirical data. There was a consistent group of people (about $60 \%$ of Brazilians) who stated they had a high level of interest in S\&T topics but who had little knowledge of these topics and who did not access scientific information much. At least a portion of these people were 'sincere', that is, they had a real interest in S\&T (as well as a generally optimistic and positive view), yet this interest and these attitudes were not associated with a concrete, active pursuit of greater information in the area.

The relation between accessing information and attitudes must be problematized. People who are more informed (e.g., those who claim to know the name of a research institution or of a scientist or who access scientific communication) do not simply present positive attitudes, for two reasons. On the one hand, non-informed people also express positive attitudes toward S\&T; on the other, informed people with higher educational levels may have attitudes that differ from those of people who access information less, but these attitudes are not necessarily "more positive." To the contrary, groups characterized by greater education or more information tend to be cautious or critical toward some specific aspects of S\&T. Our data point to indexes where as information increases, people tend to value the power associated with scientific knowledge and technology while still underlining the associated risks and danger.

This is not conclusive evidence, of course, but these data do warrant further examination through broad research, which we are already in the process of developing. To this end, we must rely not only on surveys but also on focus groups, interviews, studies of the media, and studies of public reception. Moreover, research must be conducted on the perception of specific actors, like children and adolescents, teachers, and politicians. 


\section{NOTES}

${ }^{1}$ On the concepts of 'scientific literacy' and 'science literacy', see, for example, Laugksch (2000); Durant (1993); and Burns, O'Connor, Stocklmayer (2003). On the broader notion of 'scientific culture', see Albornoz et al. (2003).

${ }^{2}$ Concomitant with the appearance of Brazilian initiatives was an Ibero-American effort to construct indicators of social perceptions of S\&T. In 2001, a collaborative initiative by the Organization of Ibero-American States (OEI), the Network for Science and Technology Indicators (RICYT), and a number of Brazilian institutions resulted in the Project for the Development of an Ibero-American Standard of Indicators of Social Perception, Scientific Culture, and Citizen Participation in S\&T (Projeto de Desenvolvimento de um Padrão Iberoamericano de Indicadores de Percepção Social, Cultura Científica e Participação Cidadã em C\&T), which led to the 2003 application of a pilot survey in various cities of the region and to the 2007 application of a survey in large cities in eight countries (Colombia, Argentina, Venezuela, Spain, Portugal, Panama, Chile, and Brazil), with over 8,000 respondents. For a discussion of these data, see Polino, Castelfranchi (2012).

${ }^{3}$ During the Cold War, for example, one of the questions used to ascertain whether or not someone was 'scientifically literate' was: "When milk is boiled, does this eliminate its radioactivity?" Today, however, a precise response to these questions is considered essential: "Do antibiotics kill bacteria or viruses?" or "Does the oxygen that we breathe come from plants?"

${ }^{4}$ The study was conducted by the company CP2 Consultoria, Pesquisa e Planejamento Ltda.

${ }^{5} 52.1 \%$ of the respondents were women and $47.9 \%$, men. Of all respondents, $10 \%$ had completed college while $31 \%$ had completed high school or some college. About one-fifth (19\%) of the sample stated that their income was equivalent to one minimum wage at most (R\$510 per month, or roughly \$290), while $16 \%$ said that they earned more than five minimum wages (R $\$ 2,550$ per month, or roughly $\$ 1,461)$.

${ }^{6}$ Based on item response theory, the Icic variable was built from the set of questions on the consumption of scientific information.

7 The regression tables portray only those variables displaying statistical significance at the levels of $1 \%$ and $5 \%$.

\section{REFERENCES}

ALBORNOZ, Mario et al.

Proyecto indicadores iberoamericanos de percepción pública, cultura científica y participación ciudadana: informe final. Buenos Aires: OEI/Ricyt/Cyted. 2003.

ALLUM, Nick C.; BOY, Daniel; BAUER, Martin W. European regions and the knowledge deficit model. In: Bauer, Martin; Gaskell, George (Ed.). Biotechnology: the making of a global controversy. Cambridge: Cambridge University Press. p.224243. 2002.

ALLUM, Nick et al.

Science knowledge and attitudes across cultures: a meta-analysis. Public Understanding of Science, London, v.17, n.1, p.35-54. 2008.

ARGENTINA.

Secretaría de Ciencia, Tecnología e Innovación Productiva (Secyt). La percepción de los argentinos sobre la investigación científicas en el país: segunda encuesta nacional. Buenos Aires: Secyt. 2007.

ARGENTINA.

Secretaría de Ciencia, Tecnología e Innovación Productiva (Secyt). Los argentinos y su visión de la ciencia y la tecnología: primera encuesta nacional de percepción pública de la ciencia. Buenos Aires: Secyt. 2003.

BAUER, Martin; DURANT, John; EVANS, Geoffrey.

European public perceptions of science. International Journal of Public Opinion Research, Oxford, v.6, n.2, p.163-186. 1994.

BAUER, Martin W.; ALLUM, Nick; MILLER, Steve. What have we learnt from 25 years of PUS research: liberating and widening the agenda? Public Understanding of Science, London, v.15, n.1, p.1-17. 2007.

BODMER, Walter.

Public understanding of science. London: Royal Society. 1985.

BRASIL.

Ministério da Ciência, Tecnologia e Inovação/ Museu da Vida. Percepção pública da ciência e tecnologia no Brasil: resultados da enquete de 2010. Brasília: Ministério da Ciência, Tecnologia e Inovação. 2010. Disponível em: http://www. mct.gov.br/upd_blob/0214/214770.pdf. Acesso em: 20 ago. 2013. 2010. 
BRASIL.

Ministério da Ciência, Tecnologia e Inovação/ Museu da Vida. Percepção pública da ciência e tecnologia no Brasil: relatório de pesquisa. Brasília: Ministério da Ciência, Tecnologia e Inovação. 2007.

BURNS, Terry. W.; O'CONNOR, John.; STOCKLMAYER, Susan. M.

Science communication: a contemporary definition. Public Understanding of Science, London, v.12, n.2, p.183-202. 2003.

CASTELFRANCHI, Yurij.

Scientists to the streets: science, politics and the public moving towards new osmoses. Journal of Science Communication, v.1, n.2. 2002. Disponível em: http://jcom.sissa.it/archive/01/02/F010201.

Acesso em: 2 ago. 2013. 2002.

CASTELFRANCHI, Yurij; PITRELLI, Nico. Come si comunica la scienza? Roma: Laterza. 2007.

CNPq/GALLUP.

O que o brasileiro pensa da ciência e da tecnologia? Rio de Janeiro: CNPq/GALLUP. 1987. Disponível em: http://semanact.mct.gov.br/index.php/ content/view/907.html. Acesso em: 2 ago. 2013. 1987.

\section{COLOMBIA}

Departamento Administrativo de Ciencia, Tecnología e Innovación/Colciencias. La percepción que tienen los colombianos sobre la ciencia y la tecnología. Bogotá: Panamericana formas e impresos. 2004.

DURANT, John R.

What is scientific literacy? In: Durant, John R.; Gregory, Jane (Ed.). Science and culture in Europe. London: Science Museum. p.129-137. 1993.

DURANT, John R.; EVANS, Geoffrey A.; THOMAS, Geoffrey P.

The public understanding of science. Nature, London, n.340, p.11-14. 1989.

DURANT, John; BAUER, Martin; GASKELL, George.

Biotechnology in the public sphere. London: Science Museum. 1998.

EC.

European Commission. Eurobarometer 2005: europeans, science and technology. Luxembourg: European Commission. 2005.

EC.

European Commission. Eurobarometer:

Europeans, science and technology. Brussels: European Commission. 2001. Disponível em: http://ec.europa.eu/public_opinion/archives/ ebs/ebs_154_en.pdf. Data de acesso: 1 ago. 2013. 2001.
EC.

European Commission. The Europeans and biotechnology. Brussels: European Commission. 2000. Disponível em: http://ec.europa.eu/public_ opinion/archives/ebs/ebs_134_en.pdf. Data de acesso: 8 ago. 2013. 2000.

EC.

European Commission. Eurobarometer 46.1: European opinions on modern biotechnology. Luxembourg: Office for Official Publications of the European Communities. 1997.

EC. European Commission. Europeans, science and technology: public understanding and attitudes. [s.l.]: European Commission. 1993.

EC.

European Commission. Opinions of Europeans on biotechnology in 1991. [s.1.]: European Commission. 1991. Disponível em: http:// ec.europa.eu/public_opinion/archives/ebs/ ebs_061_en.pdf. Data de acesso: 8 ago. 2013. 1991.

EVANS, Geoffrey; DURANT, John.

The relationship between knowledge and attitudes in the public understanding of science in Britain. Public Understanding of Science, London, v.4, n.1, p.57-74. 1995.

GASKELL, George; BAUER, Martin. Biotechnology, 1996-2000: the years of controversy. London: Science Museum. 2001.

GODIN, Benoit; GINGRAS, Yves.

What is scientific and technological culture and how is it measured? A multidimensional model. Public Understanding of Science, London, v.9, n.1, p.43-58. 2000.

HILGARTNER, Stephen.

The dominant view of popularization: conceptual problems, political uses. Social Studies of Science, London, v.20, n.3, p.519. 1990.

IRWIN, Alan; WYNNE, Brian.

Misunderstanding science?: the public reconstruction of science and technology. Cambridge: Cambridge University Press. 1996.

LAUGKSCH, Rudi C.

Scientific literacy: a conceptual overview. Science Education, New York, v.84, n.1, p.71-94. 2000.

MARTIN, Sam.; TAIT, Joyce.

Attitudes of selected public groups in the U.K. to biotechnology. In: Durant, John (Ed.). Biotechnology in public: a review of recent research. London: Science Museum Publications. p.28-41. 1992. 
MEAD, Margaret; METRAUX, Rhoda. Image of the scientist among high school students: a pilot study. Science, Washington, n.126, p.386-387. 1957.

\section{MÉXICO}

Consejo Nacional de Ciencia y Tecnologia (Conacyt). Encuesta sobre la percepción pública de la ciencia y la tecnología en México. México: Conacyt. 2003.

MÉXICO.

Consejo Nacional de Ciencia y Tecnologia (Conacyt). Indicadores de actividades científicas y tecnológicas, 1998. México: Conacyt. 1999.

MILLER, Jon D.

The measurement of civic scientific literacy. Public Understanding of Science, London, v.7, n.3, p.203-223. 1998.

MILLER, Jon D.

Scientific literacy: a conceptual and empirical review. Daedalus, Cambridge, v.112, n.2, p.29-48. 1983.

MILLER, Jon D.; PARDO, Rafael.; NIWA, Fujio. Public perceptions of science and technology: a comparative study of the European Union, the United States, Japan, and Canada. Chicago: Academy of Sciences. 1997.

OECD.

Organization for Economic Co-operation and Development. Promoting public understanding of science and technology. Paris: OECD. 1997a.

OECD.

Organization for Economic Co-operation and Development. Science and technology in the public eye. Paris. 1997b. Disponível em: http://www. oecd.org/dataoecd/9/11/2754356.pdf. Acesso em: 20 ago. 2013. 1997b.

PANAMÁ.

Secretaria Nacional de Ciencia y Tecnologia. Indicadores de percepción social de la ciencia y la tecnología en Panamá, 2001. Panamá: Senacyt. 2001.
PARDO, Rafael; CALVO, Felix.

The cognitive dimension of public perceptions of science: methodological issues. Public Understanding of Science, London, v.13, n.3, p.203-227. 2004.

PARDO, Rafael; CALVO, Felix.

Attitudes toward science among the European public: a methodological analysis. Public Understanding of Science, London, v.11, n.2, p.155-195. 2002.

POLINO, Carmelo; CASTELFRANCHI, Yurij. Information and attitudes towards acience and technology in Iberoamerica. In: Bauer, Martin; Shukla, Rajesh; Allum, Nick (Org.). The culture of science: how the public relates to science across the globe. New York: Routledge. p.155-175. 2012.

PRIEST, Susanna $H$.

Misplaced faith: communication variables as predictors of encouragement for biotechnology development. Science Communication, v.23, n.2, p.97-110. 2001.

ROTH, Wolff-Michael; LEE, Stuart.

Scientific literacy as collective praxis. Public Understanding of Science, London, n.11, p.33-56. 2002.

SAGAN, Carl.

O mundo assombrado por demônios: a ciência vista como uma vela na escuridão. São Paulo: Companhia das Letras. 1996.

STOKES, Donald E.

O quadrante de Pasteur: a ciência básica e a inovação tecnológica. Campinas: Editora da Unicamp. 2005.

STURGIS, Patrick J.; ALLUM, Nick C.

Science in society: re-evaluating the deficit model of public attitudes. Public Understanding of Science, London, v.13, n.1, p.55-74. 2004.

WITHEY, Stephen B.

Public opinion about science and scientists. Public Opinion Quarterly, London, v.23, n.3, p.382-388. 1959. 